\title{
A study to assess the risk factors and correlates of pre - eclamptic toxemia in Bundelkhand region of Madhya Pradesh
}

\author{
Shikha Pandey, Ramesh Pandey \\ Correspondence: Dr. Ramesh Pandey, Associate Professor, Department of Medicine, \\ Bundelkhand Medical College (BMC), Sagar, Madhya Pradesh, India; Email - \\ pandeyrameshdr1999@gmail.com
}

Distributed under Creative Commons Attribution-Share Alike 4.0 International.

\begin{abstract}
Objective: To identify the risk factors for pre-eclampsia in Bundelkhand region of Madhya Pradesh. Methodology: This case control study was conducted in tertiary care hospital in the year of 2015 from January to December. Hundred numbers of pregnant women with hypertension after the 20th week of gestation along with proteinuria were taken as cases, and similar numbers of pregnant women without preeclamptic toxemia (PET) were taken as control group. Results: The significant determinants identified for PET were history of chronic hypertension $(\mathrm{OR}=6.69)$, history of diabetes $(\mathrm{OR}=8.66)$, pre- pregnancy $\mathrm{BMI}$ of $\geq 25$ ( $\mathrm{OR}=7.56$ ), history of renal disease ( $\mathrm{OR}=5.6$ ), family history of hypertension ( $\mathrm{OR}=5.48)$, and twin pregnancy $(\mathrm{OR}=5.73)$. Conclusion: The most important factors in the occurrence of PET were BMI, diabetes, and history of chronic hypertension.
\end{abstract}

Keywords: Pregnancy, odds ratio, risk factors, preeclampsia.

Pre-eclamptic toxemia is pregnancy induced hypertension $(\mathrm{PIH})$ manifesting in second trimester and affecting multiple systems. Exact etiology is still unknown. It can lead to various complications both for the mother and the baby. Hypertension complicates an estimated 9-10 \% of all pregnancies. Certain risk factors are associated with PET. The factors that are associated with pre-eclampsia among the mothers include diabetes, renal disease, primiparity, chronic hypertension, age above 30 years, obesity, multiple pregnancy and family history of pre-eclampsia ${ }^{1-4}$. Preeclampsia and eclampsia are the leading cause of infant and maternal death in Bundelkhand. In this reference, a case control study was conducted Bundelkhand Medical College (BMC) Hospital to assess and determine the risk factors for pre-eclampsia.

\section{Materials and Method}

This study was conducted in Bundelkhand Medical College Hospital Sagar Madhya Pradesh in the year of 2015 from January to December. Hundred cases and 100 controls were selected. This is calculated by taking odds ratio of 3 , power at $80 \%$, significant level was 0.05 , and controls with exposure were 0.1 proportion. Pregnant women with PET comprised those with

Received: $2^{\text {nd }}$ February 2017. Accepted: $26^{\text {th }}$ March 2017.

Pandey S, Pandey R. A study to assess the risk factors and correlates of pre - eclamptic toxemia in Bundelkhand region of Madhya Pradesh. The New Indian Journal of OBGYN. 2017; 4(1):27-30 
Table 1: Risk Factors of pre-eclampsia

\begin{tabular}{|c|c|c|c|c|c|}
\hline \multicolumn{2}{|l|}{ Factors } & \multirow{2}{*}{$\begin{array}{l}\text { Cases } \\
10\end{array}$} & \multirow{2}{*}{$\begin{array}{l}\text { Control } \\
1\end{array}$} & \multirow{2}{*}{$\begin{array}{l}\text { Crude OR } \\
9.63\end{array}$} & \multirow{2}{*}{$\begin{array}{l}95 \% \mathbf{C L} \\
1.15-80.63\end{array}$} \\
\hline $\mathrm{H} / \mathrm{O} \quad \mathrm{PIH}$ in & Present & & & & \\
\hline $\begin{array}{l}\text { earlier } \\
\text { pregnancy }\end{array}$ & Absent & 90 & 99 & - & - \\
\hline mass & $>25$ & 13 & 3 & 11.27 & $2.22-57.20$ \\
\hline \multirow{2}{*}{ index } & $18.5-24.9$ & 82 & 84 & 2.54 & $0.86-7.44$ \\
\hline & $<18.5$ & 5 & 13 & - & - \\
\hline \multirow{2}{*}{$\begin{array}{l}\text { Multiple } \\
\text { pregnancy }\end{array}$} & Present & 9 & 2 & 4.85 & $1.02-23.03$ \\
\hline & Absent & 91 & 98 & - & - \\
\hline \multirow{2}{*}{$\begin{array}{l}\text { Chronic } \\
\text { hypertension }\end{array}$} & Present & 15 & 2 & 8.65 & $1.92-38.90$ \\
\hline & Absent & 85 & 98 & - & - \\
\hline \multirow[t]{2}{*}{ Renal diseases } & Present & 10 & 1 & 11.0 & $1.38-87.64$ \\
\hline & Absent & 90 & 99 & - & - \\
\hline \multirow{2}{*}{$\begin{array}{l}\text { Family h/o } \\
\text { hypertension }\end{array}$} & Present & 14 & 2 & 7.98 & $1.76-36.09$ \\
\hline & Absent & 86 & 98 & - & - \\
\hline \multirow[t]{2}{*}{ Parity } & Multi & 37 & 27 & 1.59 & $0.87-2.89$ \\
\hline & Primi & 63 & 73 & - & - \\
\hline
\end{tabular}

controls. Around $15 \%$ of cases and $2 \%$ of controls had chronic hypertension. The percentage of multigravida was high among cases as compared to controls. On analyzing we found that multiple pregnancy $(\mathrm{OR}=4.85)$, history of chronic hypertension $(\mathrm{OR}=8.65)$, $\mathrm{BMI} \geq 25$ (OR $=11.27)$, history of renal disease $(\mathrm{OR}=7.98)$, history of diabetes $(\mathrm{OR}=11.0)$, family history of hypertension $(\mathrm{OR}=5.4)$, history of PIH in earlier pregnancy (9.63), and were associated significantly with PET. Age group was not associated significantly with pre-eclampsia in this study. After adjustment for confounding

hypertension after the 20th week of gestation along with proteinuria and this group of women was considered as study group (cases) and pregnant women without PET were taken as control group. Cases and controls were selected following the above criteria ensuring a case control ratio of 1:1. Maternal records of the hospital from January to December 2015 were studied for history and case work up. Firstly maternal records of pre-eclampsia patients were studied and separated. Cases were selected from the separated pre-eclampsia records randomly. In the same manner controls were selected. Information relating age, parity, body mass index (BMI), twin pregnancy, history of chronic hypertension, history of diabetes, history of renal dysfunction, and history of PIH in earlier pregnancy was obtained from the case records. Records were analyzed by using of SPSS version 12 and Crude odds ratios with $95 \%$ confidence intervals were analyzed. A multiple logistic regression analysis is used to assess independent effects of each variable.

\section{Results}

Most of the controls and cases were in the 20-29 year age group (76\% and 85\%). Body Mass Index (BMI) was normal among the majority of the cases and
Table 2: Related conditions in PET : Multiple logistic regression analysis

\begin{tabular}{lllll}
\hline Factors & & $\begin{array}{l}\text { Adjusted } \\
\text { OR }\end{array}$ & 95\% CL & $\begin{array}{l}\text { P - } \\
\text { value }\end{array}$ \\
\hline Parity & Multi & 1.89 & $0.96-3.70$ & 0.07 \\
& Primi & - & - & - \\
\hline Body mass & $>25$ & 7.56 & $1.32-43.37$ & $0.02^{*}$ \\
index & $18.5-24.9$ & 1.86 & $0.6-5.77$ & 0.29 \\
& $<18.5$ & - & - & - \\
\hline Multiple & Present & 5.73 & $1.13-29.10$ & $0.04^{*}$ \\
pregnancy & Absent & - & - & - \\
\hline H/O Chronic & Present & 6.69 & $1.37-32.75$ & $0.02^{*}$ \\
hypertension & Absent & - & - & - \\
\hline H/O & Present & 8.66 & $1.01-76.26$ & $0.05^{*}$ \\
Diabetes & Absent & - & - & - \\
\hline H/O Renal & Present & 5.6 & $1.12-28.04$ & $0.04^{*}$ \\
disease & Absent & - & - & - \\
\hline Family h/o & Present & 5.84 & $1.09-27.55$ & $0.04^{*}$ \\
hypertension & Absent & - & - & - \\
\hline P value < 0.05 is significant & & \\
\hline
\end{tabular}

variables, six variables were associated with PET in multivariate logistic regression analysis. The significant determinants identified for PET were history of chronic hypertension $(\mathrm{OR}=6.69)$, history of diabetes $(\mathrm{OR}=8.66)$, pre- pregnancy $\mathrm{BMI}$ of $\geq 25$ (OR $=7.56)$, history of renal disease $(\mathrm{OR}=5.6)$, family 
history of hypertension $(\mathrm{OR}=5.48)$, and twin pregnancy $(\mathrm{OR}=5.73)$. The most important factors in the occurrence of PET were BMI, diabetes, and history of chronic hypertension.

\section{Discussion}

This study has been conducted in B.M.C hospital attached to a medical institution. Most of the deliveries in the district are home deliveries with the aid of MPW (multi purpose workers) /dais or conducted in private hospital. There is no proper system that can record the history at home, majority of hospital and public sectors like primary health centers and community health centers. This study showed that the pre-pregnancy BMI of $\geq 25$, history of chronic hypertension, history of diabetes, history of renal dysfunction, family history of hypertension, and twin pregnancy were significant independent risk factor for PET. Various studies found that pre - pregnancy BMI is an important risk factor for pre-eclampsia ${ }^{5-8}$.

Chronic hypertension is a common problem in nonpregnant women and increases the incidence of preeclampsia. We found that chronic hypertension is one of the main risk factor of pre-eclampsia. Family history of hypertension was also associated independently with PET $^{9}$. Renal dysfunction ${ }^{10}$ and diabetes ${ }^{11,12}$ are wellknown for adverse pregnancy outcomes. In this study both of these factors were independently linked. The possibility of pre-eclampsia nearly increases by 8.7 times in pregnancy diabetes. The probability of preeclampsia was estimated to be $<0.05$ for those with family history of diabetes. Renal dysfunction is found to be a risk factor for pre-eclampsia in other studies ${ }^{10}$.This study found that twin pregnancy increases the risk of pre-eclampsia by 5.7 times. In this study, age and parity were not found to be linked with preeclampsia. The difference in the present study and other studies could be due to the differences in the hospital-based study and population-based. Second reason could be the inclusion of mothers from the lower socioeconomic status group who came to the hospital. These mothers were found to be at lower risk. Most of cases and controls admitted were from the lower and middle socioeconomic group; hence it can be biased to an extent. But in other hospitals, selection bias may be more where more affluent urban population attend.

\section{Conclusion}

From the findings of this study, it was observed that BMI, diabetes and history of chronic hypertension were the most important factors in the occurrence of PET. This study information of the region can be quit helpful in planning maternity services at a district level to prevent the complications for the mother and the baby.

\section{Conflict of interest: None. Disclaimer: Nil.}

\section{References}

1.Lee CJ, Hsieh TT, Chiu TH, Chen KC, Lo LM, Hung TH. Risk factors for pre-eclampsia in an Asian population. Int J Gynaecol Obstet. 2000; 70: 327-33. [PubMed]

2.Eskenazi B, Fenster L, Sidney S. A multivariate analysis of risk factors for preeclampsia. JAMA.1991; 266: 237-41. [PubMed]

3.Mahomed K, Williams MA, Woelk GB, Jenkins-Woelk L, Mudzamiri S, Madzime S, et al. Risk factors for preeclampsia-eclampsia among Zimbabwean women: Recurrence risk and familial tendency towards hypertension. J Obstet Gynaecol. 1998; 18: 218-22. [PubMed]

4.Duckitt K, Harringt D. Risk factors for pre-eclampsia at antenatal booking: Systematic review of controlled studies. BMJ. 2005; 330: 565. [PubMed]

5.O'Brien TE, Ray JG, Chan WS. Maternal body mass index and the risk of preeclampsia: a systematic overview. Epidemiology. 2003; 14(3): 368-74.

6.Hauger MS, Gibbons L, Vik T, Belizan JM. Prepregnancy weight status and the risk of adverse pregnancy outcome. Acta Obstet Gynecol Scand. 2008; 87(9): 953-59.

7.Driul L, Cacciaguerra G, Citossi A, Martina MD, Peressini L, Marchesoni D. Prepregnancy body mass index and adverse pregnancy outcomes. Arch Gynecol Obstet. 2008; 278(1): 23-6.

8.Bodnar LM, Catov JM, Klebanoff MA, Ness RB, Roberts JM. Prepregnancy body mass index and the occurrence of severe hypertensive disorders of pregnancy. Epidemiology. 2007; 18(2): 234-39. 
9.Ness RB, Markovic N, Bass D, Harger G, Roberts JM. Family History of Hypertension, Heart Disease, and Stroke among Women Who Develop Hypertension in Pregnancy. Obstet Gynecol. 2003; 102:1366-71. [PubMed]

10.Vikse BE, Irgens LM, Bostad L, Iversen BM. Adverse perinatal outcome and later kidney biopsy in the mother. $\mathrm{J}$ Am Soc Nephrol. 2006; 17: 837- 45.

11.Hanson U, Persson B. Epidemiology of pregnancyinduced hypertension and preeclampsia in type 1 (insulindependent) diabetic pregnancies in Sweden. Acta Obstet Gynecol Scand. 1998; 77: 620-24.
12.Klemetti MM, Laivuori H, Tikkanen M, Nuutila M, Hiilesmaa V, Teramo K. White's classification and pregnancy outcome in women with type 1 diabetes: a population-based cohort study. Diabetologia. 2015; 59: 92-100.

Shikha Pandey ${ }^{1}$, Ramesh Pandey ${ }^{2}$

${ }^{1}$ Associate Professor, Department of Obstetrics and Gynaecology, BMC, Sagar, Madhya Pradesh, India; ${ }^{2}$ Associate Professor, Department of Medicine, BMC, Sagar, Madhya Pradesh, India. 